\title{
Retroactive inhibition as a function of the conceptual structure of original and interpolated lists
}

\author{
JAMES L. ROGERS, JR., and BENTON J. UNDERWOOD \\ Northwestern University, Evanston, Illinois 60201
}

\begin{abstract}
Subjects learned either a hierarchically structured serial list of concept instances or a list made up of the same words but without structure. These two original lists were followed by one of four interpolated lists varying in number of hierarchical levels and consisting of new instances of the concepts which occurred in the original lists. Recall of the original structured list showed heavy retroactive inhibition, with the magnitude being independent of the number of conceptual levels in the interpolated lists. For the unstructured original list, retroactive inhibition decreased as the number of conceptual levels in the interpolated list increased. Some mechanisms believed involved in producing these outcomes were discussed.
\end{abstract}

The present study deals with the retroactive inhibition resulting from various conceptual relationships existing between two tasks. It was prompted by previous work (Underwood \& Zimmerman, 1973; Underwood, Shaughnessy, \& Zimmerman, 1974), the essential nature of which will be described. Constant-order, paired-associate lists were used in which numbers were the stimulus terms, and words were the response terms. The stimulus numbers occurred in sequence, e.g., 1 through 16 in a 16-pair list. The response words represented several instances of each of several concepts or categories. If the several instances of a category occupied adjacent positions, hence were paired with consecutive numbers, learning was much faster than if the numbers and words were paired randomly.

An interpretation of such results would seem to revolve around the covert or implicit occurrence of the category name, this name being elicited by the instances of the category. Assume that the first four pairs in a list were 1-horse, 2-goat, 3-hyena, and 4-tiger. It is believed that in the optimal case all four of the words elicit (implicitly) the word "animal." Thus, "animal," being a frequent response, quickly becomes associated with the initial numbers in the list. If the stimulus numbers 5 through 8 were paired with instances of another category, such as plants, "plants" would quickly become associated with the second block of numbers. This is not to say that the category name is intitially associated with each number independently; rather, it would appear that the association is between blocks of numbers or positions. The associations might be as crude as: first block, "animals," second block, "plants," and so on. This knowledge, however, markedly restricts the positioning possibilities for the words. As learning proceeds, the size of the block becomes precisely delimited and, because the stimulus numbers and positions in the list are perfectly confounded, it seems necessary to speak of number-position blocks as becoming the effective stimuli for the implicit category names. These names, in turm, lead to the particular instances of the category with which the subject responds and which must be properly ordered within each block. The words may be ordered within a list to form a hierarchical structure of categories and, if the appropriate implicit responses occur, the hierarchy may result in a further delimitation of the positioning possibilities. In the example given above of the four animal names, a distinction (by the subject) between tame animals and wild animals would still further restrict the positioning possibilities of a given category instance.

Let us assume that a subject has learned a list in which the implicit conceptual responses play the role described above. We now present a second list with the same stimulus numbers and with the response words representing new instances of the categories used in the first list. However, the number-position blocks associated with the categories in the first list are rearranged in the second. For example, if the first list consists of four instances of each of four categories, the arrangement of the categories for the two lists might be as follows:
First List

First Block: Animals

Second Block: Plants

Third Block: Instruments

Fourth Block: Weapons

\section{Second List}

First Block: Instruments

Second Block: Weapons

Third Block: Animals

Fourth Block: Plants
In transfer terminology, the arrangement represents an $\mathrm{A} \cdot \mathrm{Br}$ paradigm between the two lists when the associations are viewed as holding between number-blocks and the implicit category names. Therefore, it would appear that in learning the second list, these associations might be unlearned and therefore provide a basis for retroactive inhibition.

There are two other potential sources of unlearning in the above arrangement of the two lists. Because the specific category instances are different for the two lists, the instances in the first list may be unlearned; this 
might be expected because of the A-B, A-D relationship between the category names and the different response terms to be associated with them in the two lists. The third possible source of interference occurs if the subject does not employ implicit conceptual responses in learning. Under these circumstances, he is still faced with an A-B, A-D relationship between stimulus numbers and the response terms in the two lists.

Given the appropriateness of the above analysis, there seems to be little doubt that some retroactive inhibition would be observed. Such expectations are supported by work with other tasks which indicate that implicit conceptual responses are sources of interference. In free-recall learning, for example, the categorizing response appears to produce retroactive inhibition even when position knowledge is not required by the task (e.g., Shuell, 1968; Royer, 1973). However, insofar as we have been able to determine, no direct comparison has been made between the amount of retroactive inhibition produced by categorized lists and the amount produced by noncategorized lists, although the evidence shows that sizeable amounts of retroactive inhibition will occur when unrelated lists of words are used in free recall (e.g., Postman \& Kepple, 1967). Sowder (1973, Experiment II) has shown that when three instances of the same concept are used as stimulus terms in original learning of a paired-associate list, followed by three new instances and different response terms in the interpolated list, retroactive inhibition occurs. Although such studies seem to implicate implicit conceptual responses in retroactive inhibition, they do not afford evidence relating to the relative magnitudes of interference to be expected in the present study. The reasons for this will become clear as the full scope of the present experiment is described.

There were two original lists of 16 word-number pairs. Both lists had exactly the same response words, but they were ordered differently in the two lists. In one case the ordering was such that a hierarchical conceptual structure of three levels was coordinated with number-position blocks. The lowest level involved a block of two positions, the next a block of four (which included the lower level) and the highest level, a block of eight which subsumed the two lower levels. In the other original list, the words were assigned to numbers in such a way as to make the conceptual relationships quite inappropriate for positioning the instances by blocks.

The second independent variable was the conceptual structure of the interpolated lists. These lists had the same number stimuli as did the original lists, and the response words were new instances of the same categories which appeared in the first list. There were four different interpolated lists but all involved the same 16 words; the differences occurred only in the pairing with the number stimuli, hence with the ordering. At one extreme they were ordered in such a way as to form a three-level hierarchical structure, thus corresponding to the structure of one of the original lists. However, the number-position blocks coordinated with the three levels were different from those used in the first list. This particular combination of original and interpolated lists was used earlier to describe the potential sources of interference.

At the other extreme of structure among the four different interpolated lists was one in which the category information could not mediate block positioning of the instances. Thus, this list, having zero structure, corresponds to the original list with zero structure. According to the analysis made earlier, these two lists should form a classical A-B, A-D paradigm in which the interference, and unlearning, should occur for the associations between the stimulus numbers and the response words with no involvement of interference based on conceptual relationships. In between the two extremes of structure for the interpolated lists as described, were two lists which differed in the number of conceptual levels associated with number-position blocks. In one of these, the lowest conceptual level was eliminated, and in the other, the lowest two levels were eliminated. In summary, the four interpolated lists represented $3,2,1$, and 0 conceptual levels coordinated with the number-position blocks. Since all four interpolated lists were used with each of the two original lists, eight conditions or eight original-interpolated list combinations resulted.

In the analysis of possible sources of unlearning which was given above, reference was made only to one of the eight conditions, namely, to the condition in which the original and interpolated lists both had three intact conceptual levels. It was possible to identify three possible sources of interference in that condition. However, in considering all eight conditions, the expectations concerning relative amounts of retroactive inhibition become clouded because of two unknowns. First, at least one secondary variable is correlated with the manipulations of structure. If the original list has high structure, the interpolated list low structure, differentiation between the two lists might be higher than if the two lists had the same structure. If, in tum, differentiation influences retroactive inhibition, the amount will differ across conditions.

The second reason why it is difficult to predict relative amounts of retroactive inhibition stems from the fact that we know essentially nothing about the magnitudes of interference in the classical paradigms when these paradigms hold for sets of conceptually related items. Thus, although it is possible to identify an $\mathrm{A}-\mathrm{Br}$ paradigm, and two A-B, A-D paradigms, we should not necessarily expect the unlearning produced by any one of them to be equivalent when applied to different conceptual levels. All of this is to indicate that the present study must be considered to be exploratory in nature. Our analysis points to the fact that retroactive inhibition should occur in all eight conditions, but only 
the experiment can tell us about the relative magnitudes of the inhibition.

\section{METHOD}

\section{Lists}

The words were presented as response terms in paired-associate lists in which the stimulus terms for the 16 words were the numbers 1 through 16 . The order of the pairs was constant from trial to trial, and the stimulus terms always occurred in the order 1 through 16 . The response terms used to manipulate conceptual structure were taken from the Battig and Montague (1969) norms, and are shown in Table 1. For each list the stimulus terms were the numbers $l$ through 16 as the words are ordered in Table 1.

There were two levels of structure in the original lists, and four levels in the interpolated lists. The description of these levels follows:

Level 0: No structure.

Level 1: The 16 words represented eight blocked words of living things, and eight blocked words of nonliving things.

Level 2: This included Level-1 blocking plus a more specific blocking of four words within each Level-1 block, i.e., a block of four animal names and a block of four plant names occurred under living things, and four instrument names and four names of weapons occurred under nonliving things.

Level 3: This included Level-1 and Level-2 blocking plus a more specific blocking of two words under each Level-2 block, e.g., domestic animals and wild animals.

The two lists used in original learning (OL lists) represented either zero structure or Level-3 structure and will be identified as List 0 and List 3 . There were four levels of structure in interpolated leaming (IL lists) so that each combination of OL and IL structure may be identified by two numbers. Thus, condition or List 3-2 signifies an OL list structured at Level 3, followed by an IL list structured at Level 2 . With two levels of OL structure and four levels of IL structure, there were eight combinations of lists representing the eight experimental conditions of the experiment: Lists $0-0,0-1,0-2,0-3,3-0.3-1$, 3-2. 3-3. These list combinations will be referred to in the singular.

Looking at the OL lists in Table 1, it can be seen that the same 16 words were used for both lists; only the ordering differed. Looking at the IL lists, it can be seen that the concepts represented were identical to those represented in the OL lists; only the instances differed. All IL lists, regardless of structure, consisted of the same 16 words as response terms. Based on the individual stimulus terms, the A-B, A-D paradigm occurs between the two lists for all pairings for all combinations of OL-IL structure. For example, in List 3-3, the subject learns 1 -horse in $\mathrm{OL}$, and 1-guitar in IL. A given stimulus term was never paired in OL and IL with two instances from the most restricted concept (which consisted of two instances in each list, e.g., wild animals). Only once in each of three lists $(0-1,0-2,0-3)$ did a stimulus term in the two lists have response terms from the same four-instance concept, e.g., animals. For example, in List $0-2$, the response term to the number 16 was rifle, in $\mathrm{OL}$, dagger in $\mathrm{L}$. We tried to avoid having an appreciable number of such pairings since they represent an $A-B, A-B^{\prime}$ paradigm with respect to the category of the response terms, and positive transfer might result therefrom. It was necessary to have several cases where a stimulus number was paired with instances representing living things (and non-living things) in both lists, but since no list rule could be followed, we believe it appropriate to conclude that effectively all OL-IL list combinations represented the A-B, A-D paradigm, whether the stimulus term be viewed as the number per se, or as the position it represented.

Given that conceptual responses were mediating placement of the blocks of concept instances when List 3 was used as OL, a change in the position of the blocks should produce interference. The lists in Table 1 must again be examined to understand the nature of the manipulation for the various IL lists following the learning of List 3 as OL. For List $3-0$, of course, the change was complete in that none of the three conceptual levels present in the OL list was appropriate in IL. For List 3-1, living-nonliving remained in IL as possible position mediators, but the eight-item blocks were interchanged between OL and IL. That is, in the OL list living things were represented in the first eight positions, nonliving things in the second block of eight, but the position of these blocks was reversed in IL. For List 3-2, the eight-item blocks were also reversed, but within each the order of the subblocks of four words representing a lower-level concept remained the same as in OL, e.g., the animal block came before the plant block in both lists. Likewise, in List 3-3, the order of the still lower level of concepts (e.g., domestic animals, wild animals, trees, flowers) remained constant across the two lists within halves. Thus, relative position of the lower two conceptual levels of concepts remained the same within halves; only the halves were interchanged. We suspect, therefore, that the present procedures would not produce the maximal interference possible. Had orders of the lower-level concepts also been changed, more interference would probably have occurred.

Table 1

Response Words*

\begin{tabular}{|c|c|c|c|c|}
\hline \multirow{2}{*}{$\frac{\text { Original Lists }}{\text { List } 0}$} & \multicolumn{4}{|c|}{ Interpolated Lists } \\
\hline & List $0-0$ & List $0-1$ & List $0-2$ & List 0.3 \\
\hline $\begin{array}{l}\text { violin } \\
\text { maple } \\
\text { knife } \\
\text { tulip } \\
\text { bugle } \\
\text { goat } \\
\text { mortar } \\
\text { tiger } \\
\text { saber } \\
\text { horse } \\
\text { rose } \\
\text { hyena } \\
\text { banjo } \\
\text { oak } \\
\text { flute } \\
\text { rifle } \\
\end{array}$ & $\begin{array}{l}\text { cow } \\
\text { cello } \\
\text { birch } \\
\text { pig } \\
\text { grenade } \\
\text { saxophone } \\
\text { lon } \\
\text { dagger } \\
\text { pine } \\
\text { pistol } \\
\text { spear } \\
\text { iris } \\
\text { bear } \\
\text { guitar } \\
\text { lily } \\
\text { clarinet } \\
\end{array}$ & $\begin{array}{l}\text { cow } \\
\text { lion } \\
\text { pine } \\
\text { bear } \\
\text { iris } \\
\text { birch } \\
\text { lily } \\
\text { pig } \\
\text { guitar } \\
\text { spear } \\
\text { saxophone } \\
\text { dagger } \\
\text { pistol } \\
\text { clarinet } \\
\text { grenade } \\
\text { cello } \\
\end{array}$ & $\begin{array}{l}\text { cow } \\
\text { lion } \\
\text { pig } \\
\text { bear } \\
\text { pine } \\
\text { lily } \\
\text { iris } \\
\text { birch } \\
\text { guitar } \\
\text { saxophone } \\
\text { cello } \\
\text { clarinet } \\
\text { spear } \\
\text { grenade } \\
\text { pistol } \\
\text { dagger } \\
\end{array}$ & $\begin{array}{l}\text { cow } \\
\text { pig } \\
\text { bear } \\
\text { lion } \\
\text { pine } \\
\text { birch } \\
\text { lily } \\
\text { iris } \\
\text { guitar } \\
\text { cello } \\
\text { clarinet } \\
\text { saxophone } \\
\text { spear } \\
\text { dagger } \\
\text { pistol } \\
\text { grenade } \\
\end{array}$ \\
\hline List 3 & List $3-0$ & List 3-1 & List 3-2 & List 3-3 \\
\hline $\begin{array}{l}\text { horse } \\
\text { goat } \\
\text { hyena } \\
\text { tiger } \\
\text { maple } \\
\text { oak } \\
\text { tulip } \\
\text { rose } \\
\text { violin } \\
\text { banjo } \\
\text { bugle } \\
\text { flute } \\
\text { knife } \\
\text { saber } \\
\text { mortar } \\
\text { rifle } \\
\end{array}$ & $\begin{array}{l}\text { guitar } \\
\text { pine } \\
\text { spear } \\
\text { iris } \\
\text { pig } \\
\text { clarinet } \\
\text { pistol } \\
\text { lion } \\
\text { dagger } \\
\text { birch } \\
\text { grenade } \\
\text { bear } \\
\text { cello } \\
\text { cow } \\
\text { saxophone } \\
\text { lily }\end{array}$ & $\begin{array}{l}\text { guitar } \\
\text { spear } \\
\text { clarinet } \\
\text { pistol } \\
\text { cello } \\
\text { dagger } \\
\text { saxophone } \\
\text { grenade } \\
\text { cow } \\
\text { pine } \\
\text { bear } \\
\text { lily } \\
\text { pig } \\
\text { birch } \\
\text { lion } \\
\text { iris } \\
\end{array}$ & $\begin{array}{l}\text { guitar } \\
\text { clarinet } \\
\text { cello } \\
\text { saxophone } \\
\text { spear } \\
\text { pistol } \\
\text { grenade } \\
\text { dagger } \\
\text { cow } \\
\text { bear } \\
\text { pig } \\
\text { lion } \\
\text { pine } \\
\text { lily } \\
\text { iris } \\
\text { birch } \\
\end{array}$ & $\begin{array}{l}\text { guitar } \\
\text { cello } \\
\text { clarinet } \\
\text { saxophone } \\
\text { spear } \\
\text { dagger } \\
\text { pistol } \\
\text { grenade } \\
\text { cow } \\
\text { pig } \\
\text { bear } \\
\text { lion } \\
\text { pine } \\
\text { birch } \\
\text { lily } \\
\text { iris } \\
\end{array}$ \\
\hline
\end{tabular}

*The numbers $\&$ through 16 were the stimulus terms. 
Figure 1. Learning of the hierarchically structured list (Liat 3) as a function of position.

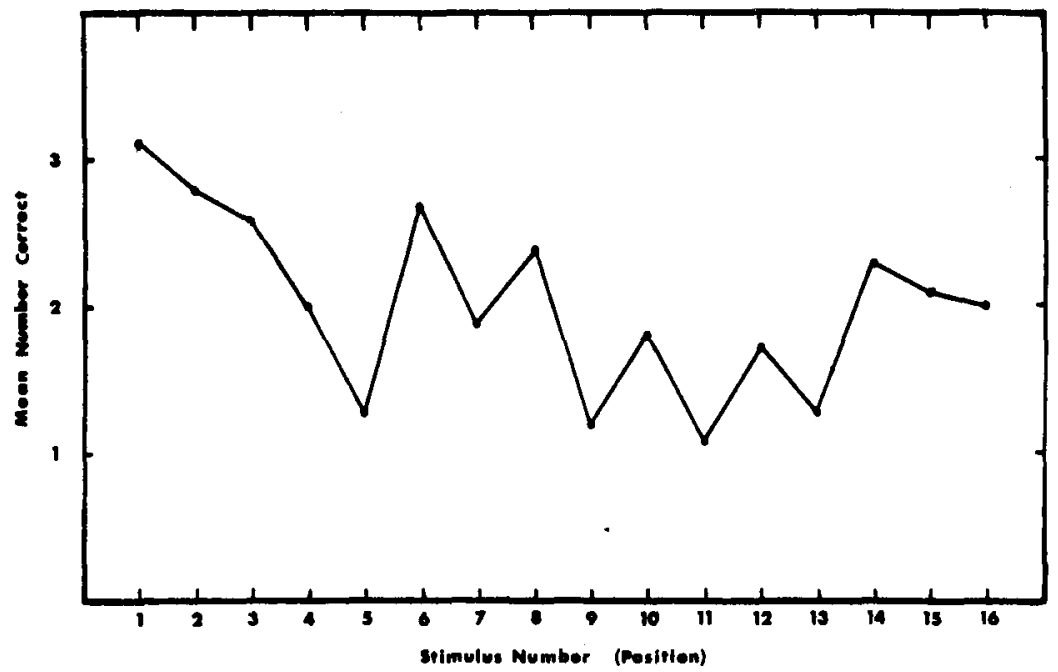

Procedure and subjects.

The eight combinations of the OL and IL lists given in Table 1 represent the experimental conditions. In addition, two control conditions were included in which only the $O L$ lists were learned. These will be identified as Lists 3-C and $0-\mathrm{C}$. The lists were presented on a memory drum by the anticipation method at a 1.5:1.5-sec rate, with a $3-\mathrm{sec}$ intertrial interval. As noted earlier, the order from trial to trial was always constant, and the order was defined by the stimulus numbers 1 through 16 . The OL was presented until 12 of the 16 responses were correctly anticipated on a single trial. The IL occurred immediately after OL and was carried to the same criterion as OL. However, if a subject failed to achieve the criterion on IL within $20 \mathrm{~min}$ he was discarded and replaced. Three subjects were replaced for this reason. The interval between the end of $\mathrm{OL}$ and recall was 20 min. The time between the end of IL and recall was filled by the subject working on the pyramid puzzle. The amount of time spent on the puzzle differed for subjects, being an inverse function of rate of IL leaming. The use of the constant interval of $20 \mathrm{~min}$ between end of $\mathrm{OL}$ and recall made it possible to use this length of "rest" for the two control groups. At recall, the subject was told that he was to give as many correct responses as possible on the first trial, and then to continue learning on subsequent trials. Four relearning trials bey ond recall were given.

The subjects were college students, with 20 assigned to each of the 10 conditions by a block-randomized schedule.

\section{RESULTS}

\section{Original learning}

A total of 100 subjects learned each of the two OL lists. The mean number of trials to reach 12 out of 16 responses correct on a single trial were $8.15(\mathrm{SD}=9.80)$ and $3.54(\mathrm{SD}=2.02)$ for Lists 0 and 3 respectively $(F=164.23)$. This merely confirms previous findings that hierarchically structured lists are learned more rapidly than are unstructured lists made up of the same words (Underwood \& Zimmerman, 1973). Neither the differences among groups learning List 0 nor the differences among the groups learning List 3 were reliable, both $F$ s being less than unity.

Differences in the patterning of overt errors were much the same as those reported earlier (Underwood \& Zimmermann, 1973; Underwood et al., 1974). These errors indicated that conceptual structure facilitated learning because the conceptual information allowed the subject to learn quickly the approximate position or stimulus number associated with a given word. Approximate position knowledge would seem, intuitively, to lead to more overt errors for the subjects given List 3 than for those given List 0 . The number of overt errors per opportunity was determined for each subject (total overt errors/total overt errors plus total no responses). The mean was .23 for the subjects leaming List 3 , and .18 for the subjects learning List 0 $[F(1 / 190)=6.00, p<.05]$.

Although the difference in tendency to make overt errors for the two lists was not large in an absolute sense, it remains possible that more correct responses were produced by guessing in learning List 3 than in learning List 0 . Within the groups leaming each list there were very wide individual differences in the number of errors per opportunity. If the subjects reached the criterion in part by guessing, a subject who guessed frequently should, by guessing, produce both more overt errors and correct responses than would a subject who infrequently guessed. Thus, overt errors per opportunity should be negatively correlated with the number of trials to reach the criterion. For the 100 subjects learning List 3 the product-moment correlation between trials to learn and errors per opportunity was -.11 . The corresponding value for the 100 subjects learning List 0 was .03 . These correlations do not indicate that guessing played a prominent role in the learning scores; at least, it can be concluded that guessing is at best responsible for only a very small part of the large difference observed in learning the two lists.

In a previous study (Underwood \& Zimmerman, 1973), it was found that subjects learning an unstructured list gave no evidence that the conceptual relationships among the words were influencing responding. This was shown by the nature of the overt errors; a subject was no more likely to give an animal name to a stimulus number appropriate for another 
animal name than he was to give a name from a completely unrelated concept. Essentially, these findings were replicated in the present study. The 100 subjects learning List 0 made 1226 overt errors. Of these, 268 $(21.9 \%)$ were appropriate for stimulus terms paired with the other three instances within the Level-2 concepts (animals, plants, instruments, weapons). Chance responding (3/16) should produce $18.8 \%$ such errors, so there was only slight evidence that the conceptual relationships among the words in the unstructured list were influencing the overt errors. On the other hand, the 100 subjects who learned List 3 made 487 overt errors of which $60.8 \%$ were appropriate to the Level-2 concepts.

The mean numbers of correct responses to each stimulus term for the 100 subjects given List 3 are shown in Figure 1. There is a primacy effect but no obvious recency effect. Of perhaps greater importance is the sawtooth nature of the curve beginning with Stimulus Number 5. The alternating peaks and falls correspond to the most specific conceptual level on the list. That is, performance was better on the second instance of the two instances than on the first. Only the last two stimulus numbers fail to show this relationship. We believe Figure 1 makes it evident that at least some of the smallest conceptual categories were influencing performance, which is to suggest that implicit conceptual responses of "trees," "flowers," "string instruments," and so on, were occurring.

\section{Interpolated learning}

Two measures of interpolated learning are plotted in Figure 2. The upper panel shows the mean numbers of correct responses on the first anticipation trial; the lower panel shows the mean numbers of trials required to reach the criterion of learning. The increase in IL list structure is plotted in equal intervals for convenience. The first fact that is apparent in both measures is that performance on IL was better when OL had been List 0 than when it had been List 3. The differences were reliable in both cases $[F(1 / 152)=30.25]$ for the first trial, and 15.27 for trials to criterion, $\mathrm{p}<.01$. Also obvious is the fact that IL was influenced by the conceptual structure of the list; the greater the number of intact conceptual levels the faster the learning $[F(3 / 152)=17.12]$ for the first trial, and 34.85 for trials to criterion. On the first trial the interaction between the two variables was reliable $[F(3 / 152)=16.27$, $\mathrm{p}<.01]$, but not on the trials-to-criterion measure $(F=.81)$. The picture is reasonably clear. Performance was better on all IL lists following the learning of OL List 0 than following OL learning of List 3, suggesting that greater interference was produced by the structured list than by the unstructured list. This interference was initially greater when the IL list had high structure than when it had low structure, but this deficit was reduced as trials continued. The differences in IL learning as a function of OL list type may be slightly overestimated, since the degree of $O L$ learning was a little higher for List 3 than for List 0 . On the last trial of OL the mean number correct for List 3 was 13.25, and for List 0 the corresponding value was 12.56 . Differences in learning which may have occurred on the last trial would expand the differences. Yet, it is quite unlikely that the relatively small difference in level of OL learning could account for the substantial differences observed in IL. Furthermore, the evidence from the intrusions in IL would support the idea that the differences were produced by differential interference.

The 80 subjects who learned List 0 produced 26 intrusions from $\mathrm{OL}$ during IL. The corresponding value for the 80 subjects given List 3 was 47 . The maximum number for any one condition was the 17 observed for List 3-3. The proportion of intrusions which could be classified as being due to conceptual relationships constituted $85 \%$ of the totals following List 0 , and $79 \%$ following List 3 . An intrusion was classified as being due to conceptual relationships if given to a stimulus number

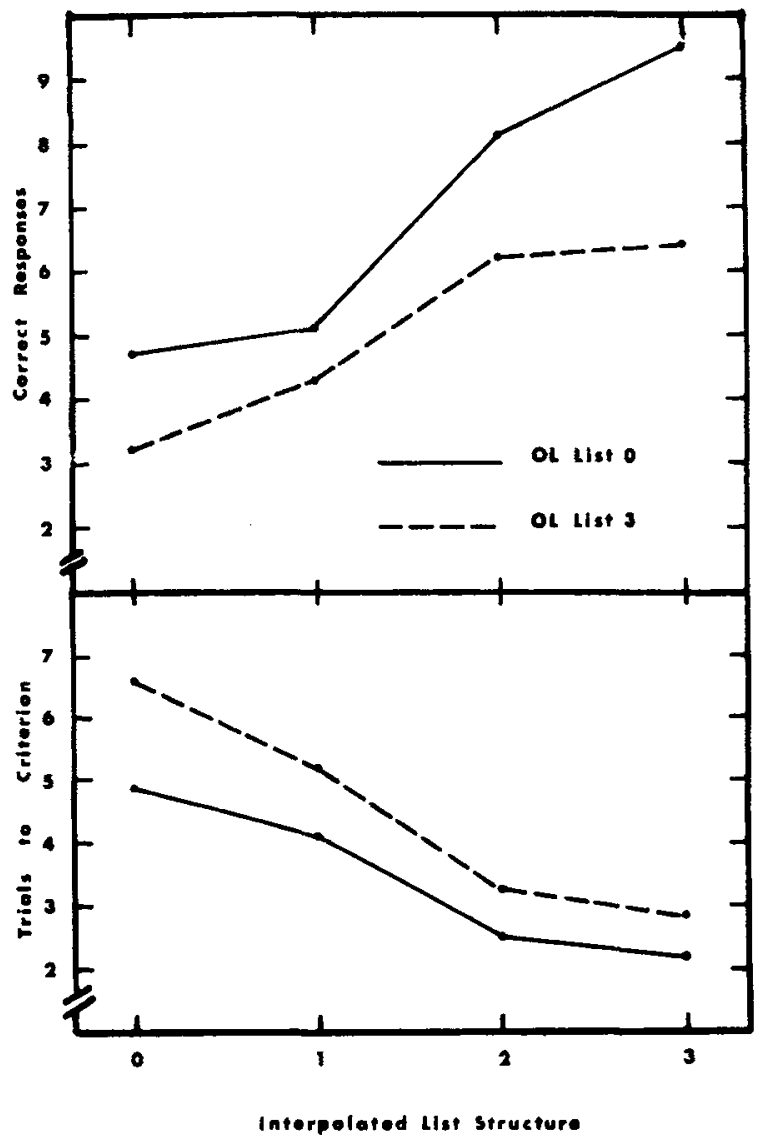

Figure 2. Measures of interpolated learning. The upper panel shows the mean number correct on the first anticipation trial as a function of OL structure $(0$ or 3$)$ and IL structure $(0,1,2,3)$. The lower panel shows the mean number of trials required to reach 12 correct responses on a single trial. The within groups mean square for the data in the upper panel was 4.71 , for those in the lower panel, 2.62 . 


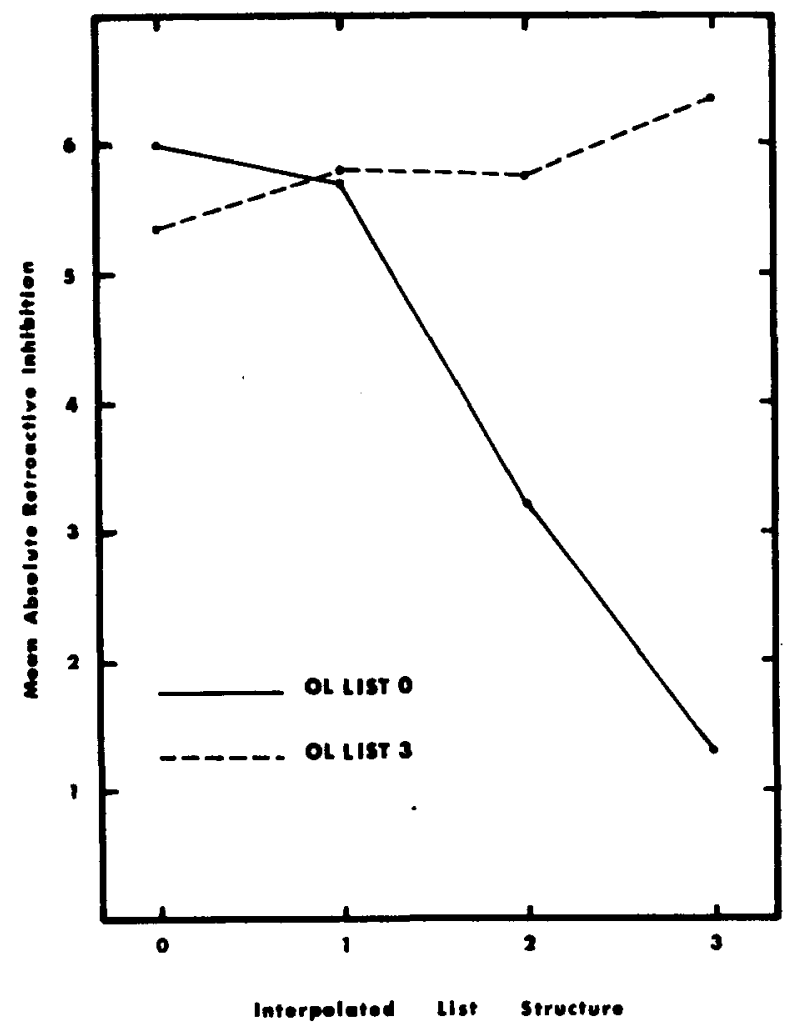

Figure 3. Absolute retroactive inhibition in recall as a function of $\mathrm{OL}$ and IL list structure. The within groups mean square was 7.10.

in IL paired with a word that belonged to the same four-instance category (e.g., animal) as did the intruding word.

It might be anticipated that misplaced response words in IL would be elicited by stimulus numbers associated with the category in OL of which the misplaced response was an instance. Thus, in List 3.3, the IL word cow might be given to stimulus terms $1,2,3$, or 4 , since the animal concept was associated with these numbers in $O L$. This in fact rarely happened. It did not happen at all for List 3-3, and only four such cases were observed for List 3-2. This seems to imply that the subjects could rather completely set aside position-concept information learned in OL when the information was inappropriate for IL.

\section{Recall}

As noted above, level of learning on the criterion trial of OL differed for the two OL lists. Compensation for the difference can be made by using loss scores obtained by subtracting the number recalled from the number given on the last OL trial. A difference score was determined for each subject, and each of these was in tum subtracted from the mean difference score for the appropriate control group to produce a measure of absolute retroactive inhibition. The subjects in the control group given List 0 lost 1.06 items over 20 min; those given List 3 lost .20 items. This difference probably is confounded by the differences in learning which occurred on the last OL trial. The absolute losses are shown in Figure 3.

The subjects who learned List 3 in OL had retroactive inhibition in the amount of approximately six items and this number was essentially uninfluenced by the nature of the IL list. For List 0 , on the other hand, retroactive inhibition decreased as IL list structure increased, and the decrease was of such magnitude that for List 0-3 there was very little retroactive inhibition observed. Statistically, all of these effects were reliable. There was less loss for List 0 than for List $3[F(1 / 152)=16.57$, $\mathrm{p}<.01]$, a decrease in the loss as list structure increased $[F(3 / 152)=4.88, p<.01]$, and the interaction was reliable $[F(3 / 152)=9.11, p<.01]$. These same relationships held for the four relearning trials given after the recall trial, although the differences were much reduced.

The intrusions from IL in recall and relearning tctaled 55 for List 0 and 134 for List 3. Intrusions for List 0-0 totaled six, while only one intrusion was noticed for List 1. All other conditions produced at least 20 intrusions as may be seen in the top row of Table 2. In the top part of Table 2 the intrusions have been classified according to the conceptual relations between the intruding word and the word it replaced. The two-instance concepts, e.g., "wild animals," represented the most restricted concepts, with the four-instance concepts being made up of two two-instance concepts, e.g., "animals," consisting of "wild animals" and "domestic animals." It is to be noted that for List 0-2, $82 \%$ of the intrusions could not be classified as being based on conceptual relations, while for List 3-3 only 6\% could not be so classified. On the other hand, as may be seen in the lower part of Table 2, a majority of the intrusions for List $\mathbf{0 . 2}$ could be accounted for on the basis of stimulus-number identity (A-B, A-D). Only $4 \%$ of the intrusions for List 3-3 were attributed to stimulus identity.

The retroactive inhibition at recall as a function of stimulus number for List 3 is shown in Figure 4. All four

Table 2

Intrusions During Recall and Relearning

\begin{tabular}{|c|c|c|c|c|c|c|}
\hline & \multicolumn{6}{|c|}{ OL-IL List Combinations } \\
\hline & $0-2$ & $0-3$ & $3-0$ & $3-1$ & $3-2$ & $3-3$ \\
\hline Total Intrusions & 28 & 20 & 36 & 26 & 26 & 46 \\
\hline $\begin{array}{l}\text { Percent Within Two- } \\
\text { Instance Concepts }\end{array}$ & 11 & 5 & 39 & 38 & 54 & 85 \\
\hline $\begin{array}{l}\text { Percent Within Four- } \\
\text { Instance Concepts }\end{array}$ & 7 & 15 & 25 & 23 & 15 & 9 \\
\hline Percent Other & 82 & 80 & 36 & 38 & 31 & 6 \\
\hline $\begin{array}{l}\text { Percent Appropriate to } \\
\text { IL Stimulus Number }\end{array}$ & 64 & 50 & 31 & 19 & 12 & 4 \\
\hline
\end{tabular}

Note-The upper section of the table shows the intrusions classified according to conceptual relationships, the lower section classified according to common stimulus numbers. 


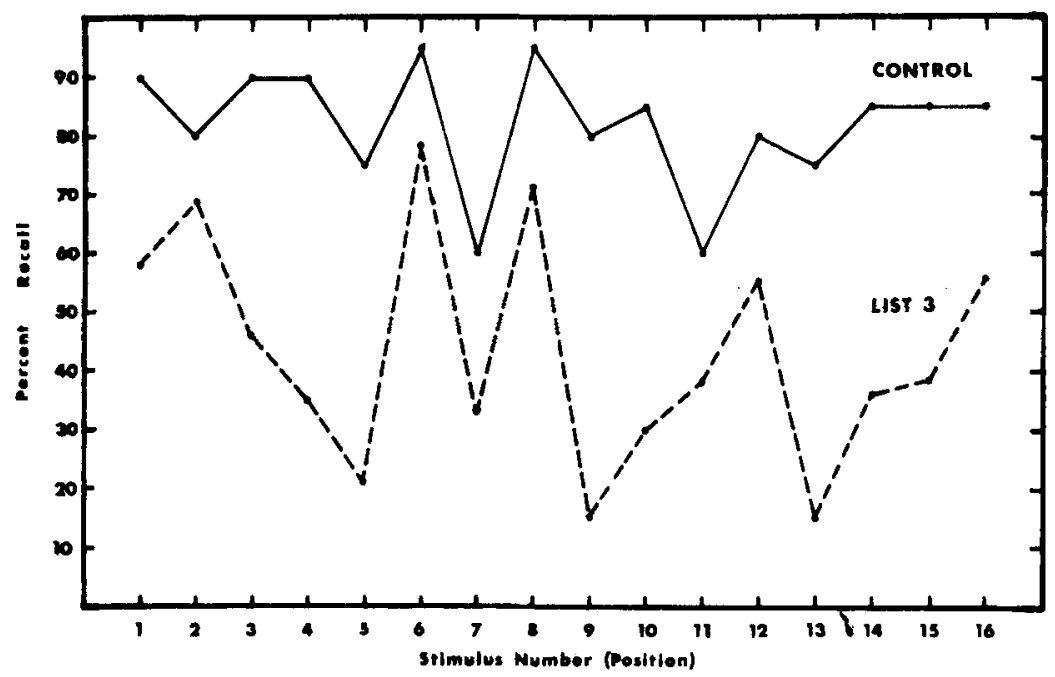

Figure 4. Recall by position for all $\mathrm{OL}$ structured lists (List 3) combined as compared with control recall (List 3-C).

conditions in which List 3 was the OL list were combined, and the percent recall for each stimulus number determined. Recall for the control list (3-C) is given for comparison purposes. The loss is apparent at all positions, but is most severe for pairs which represent the occurrence of the first instance of four-instance concepts.

\section{DISCUSSION}

The essential facts shown by this experiment were: (1) the memory for highly structured lists was severely impaired by interpolated lists of either low or high structure; (2) the memory for unstructured lists was severely impaired by unstructured interpolated lists, but was influenced relatively little by structured interpolated lists. The purpose of this discussion will be to see if post hoc decisions can be reached on the sources of unlearning. We will speak of these as sources of unlearning although we fully realize that our procedures do not neatly distinguish between unlearning and competition or interference not involving unlearning. In the introductory section we identified the presence of an $\mathrm{A} \cdot \mathrm{Br}$ paradigm for some of the conditions, and the presence of two A-B, A-D paradigms. In addition, the various OL-IL combinations were seen to differ on the similarity of list structures, hence to differ on differentiation between the two lists.

List 3-0 produced a large amount of retroactive inhibition, List $0-3$ produced a small amount. The asymmetry leads to the conclusion that a simple list differentiation hypothesis can be ruled out as having fundamental importance. If structure vs. no structure serves to differentiate the two lists, there is no apparent reason why the differentiation should not have been equivalent for List 0-3 and List 3-0. However, as will be seen, the evidence may be used to support the operation of a somewhat more complicated type of list differentiation.
In learning OL List 0 , the evidence indicates that implicit conceptual responses were not fundamentally involved in the learning. That is, the subject did not learn that stimulus number 1 was associated with a musical instrument. Were this the case, misplaced responses should occur largely to stimulus terms associated with other instances of a given concept. The evidence showed that such intralist errors were only slightly greater than was to be expected by chance responding. We do not mean to imply that the subject had no knowledge in memory of at least some of the conceptual relationships existing among the response terms. Rather, we assume that such information was present but that the subject perceived that the nature of the task was such that to attempt to respond on the basis of this conceptual information would be inimic? to performance. This is in conformance with the res'. ts of a study by Galbraith (1975) which showed that subjects can maintain independence between different types of information when the tasks demand it. In short, we assume that the subject does not learn a pair in List 0 by a conceptual mediator. The pairs may have been learned by using other types of mediators, or by rote, but not by conceptual mediators.

When List 3 occurs as OL, the evidence is quite conclusive that performance is mediated by conceptual knowledge. A single conceptual mediator will allow the subject to limit the particular number stimuli for which a word is appropriate. The positioning within a four-instance concept is aided by the presence of the two-instance, lower-level concepts. Within the two positions the subject must learn the proper ordering of the two instances and he must also learn the ordering of the two two-position concepts within the four-position concepts. Obviously, conceptual mediators will not aid this part of the learning and may indeed be sources of confusion.

We will next consider the mechanisms involved in IL and the manner in which they influence recall. List $0-0$. 
under the present perspective, is a simple A-B, A-D paradigm since, as argued above, conceptual responses play no role in the acquisition of the unstructured lists. Basically, this situation would also hold for List $0-1$, where only the living-nonliving distinction is present and, as seen in Figure 2, this broad conceptual distinction has only a small influence on IL regardless of OL list structure. However, as structure increases (Lists 0-2 and 0-3), the implicit responses for categories will occur and will be utilized by the subject in learning the list. We believe that because implicit conceptual responses are not involved in learning OL List 0 , and because they become involved in IL lists for $0-2$ and $0-3$, a means is established for clearly differentiating the two lists. That is, the subject may differentiate the lists in terms of the responses made to the stimulus terms; in $\mathrm{OL}$, conceptual responses were not made consistently to the stimulus terms, in IL, they were. As this differentiation increases, recall increases.

The combination of OL and IL lists identified as 3.3 would form an $\mathrm{A}-\mathrm{Br}$ paradigm in which conceptual responses associated with blocks of stimuli in $\mathrm{OL}$ must be shifted during IL to different blocks of stimuli. For this condition the data suggest strongly that this shifting does not result in the unlearning of associations between blocks and concepts in OL. Nearly all of the 46 intrusions in recall which occurred for this condition were given to appropriate stimulus terms in OL. That is, concept instances from IL intruded into appropriate blocks during recall. The loss, therefore, appears to lie largely in the loss of the concept instances from $\mathrm{OL}$ as a result of learning new concept instances in IL. Thus, the loss occurs as a result of the A-B, A-D relationship between the implicit concept names and the concept instances. This would be quite consistent with the results of free-recall learning as described in the introduction. The only addition is that knowledge of categories associated with particular number-position blocks in OL is uninfluenced by the acquisition of new category names to the number-position blocks in IL. This memory may have been facilitated in the present lists because the relative ordering of the two- and four-instance concepts remained constant within halves of the lists. In any event, the major loss for List 3-3 lies in the loss of response terms.

We next must consider the situations for Lists 3-0, 3.1 , and 3.2. We believe that there are two types of losses involved. For List 3-0 the implicit conceptual responses become inappropriate during IL and cease to be elicited. As a consequence, there is some loss for the particular number-position blocks in OL associated with instances of the same category. Some specific response-term unlearning will occur, perhaps from two sources. First, the category names associated with number-position blocks will probably be elicited on the initial trial or two, thus leading to a loss of the specific instances associated with the category names in OL. As trials continue, the second source develops, namely unlearning due to the A-B, A-D relationship between the specific number stimuli and the different response terms to be associated with them in the two lists. As we move to Lists 3-1 and 3-2, concept instance loss to category names increases, and item loss to specific stimulus numbers decreases. That there are these two sources of loss has been suggested by the intrusion data (Table 2). Intrusions due to specific stimulus numbers decrease from List 3-0 to List 3-3, and intrusions based on conceptual relationships increase, although the latter trend is less clear than the former.

However useful the above guesses will be in handling the results of subsequent, and more analytical studies, one clear empirical fact emerges from this experiment. The involvement of a conceptual (cognitive?) network in the acquisition of a task does not prevent the memory for that task from being severely depressed either by learning a further task which involves other conceptual networks, or by learning a further task in which simple, low-level, stimulus-response associations are required.

\section{REFERENCES}

Battig, W. F, Montague, W. E. Category norms for verbal items in 56 categories: $A$ replication and extension of the Connecticut category norms. Journal of Experimental Psychology Monograph, 1969, 80, (3, Pt. 2).

Galbraith, R. C. On the independence of attributes of memory. Joumal of Experimental Psychology: Human Learning and Memory, 1975, 104, 23-30.

Postman, $\dot{L}$., \& Keppel, G. Retroactive inhibition in free recall. Joumal of Experimental Psychology, 1967, 74, 203-211.

Royer, J. M. Within-list retroactive inhibition in free recall as a function of list organization. American Journal of Psychology $1973,86,89-101$

Shuell, T. J, Retroactive inhibition in free-recall leaming of categorized lists. Journal of Verbal Learning and Verbal Behavior, 1968, 7, 797-805.

Sowder, C. Mediated unlearning. Journal of Experimental Psychology, 1973, 100, 50-57.

Underw ood, B. J., Zimmerman, J. Serial retention as a function of hieranchical structure. Journal of Experimental Psychology, 1973, 99, 236-242.

Underwood, B. J., Shaughnessy, J. J., \& Zimmerman, J. The locus of the retention differences associated with degree of hierarchical conceptual structure. Journal of Experimental Psychology, 1974, 102, 850-862.

(Received for publication March $5,1975$. Revision received April 21, 1975.) 